\title{
Assessment of the Hydrochemical Regime and Safety of Fish in Water Bodies of Karaganda Region, Kazakhstan
}

\author{
Gulzhan Aubakirova $^{1 *}$, Zhanat Adilbekov ${ }^{2}$, Assylkhan Inirbayev ${ }^{2}$, Assel Zhamanova \\ and Aibar Akhmetov ${ }^{3}$ \\ ${ }^{1}$ Department of Hunting and Fisheries, Faculty of Veterinary Sciences and Animal \\ Husbandry, S. Seifullin Kazakh Agro-Technical University, Nur-Sultan, Kazakhstan \\ ${ }^{2}$ Department of Veterinary Sanitation, Faculty of Veterinary Sciences and Animal \\ Husbandry, S. Seifullin Kazakh Agro-Technical University, Nur-Sultan, Kazakhstan \\ ${ }^{3}$ Department of Veterinary Medicine, Faculty of Veterinary Sciences and Animal \\ Husbandry, S. Seifullin Kazakh Agro-Technical University, Nur-Sultan, Kazakhstan
}

\begin{abstract}
A B S T R A C T
This article presents the results of a study of the hydrochemical regime of water bodies in the Karaganda region, the Republic of Kazakhstan, and assesses the safety of fish. It was established that the hydrochemical regime of the water bodies was within the permissible concentration, however, a decreased permanganate oxidation was noted, which indicates a satisfactory state of water quality. Widespread infection of fish with postdiplostomatosis was revealed in assessing fish safety; in rare cases, diplostomosis and ligulosis were detected. The incidence of fish with bacteriosis was not observed, with the exception of isolated cases of aeromonosis. Exceeding the maximum permissible concentrations for residual amounts of toxic elements and radionuclides has not been established. We found that the most common fish disease in the water bodies of the Karaganda region was postdiplostomatosis, which was diagnosed in the roach in all the water bodies of three regions, and the most infection was observed in the fish of the DSU-58 reservoir in the Nurinsky district, where the infestation rate was $42.8 \%$, intensity $3-5$. Most likely this is due to the presence of fish-eating birds (herons and tree frogs) and a large number of gastropods in these reservoirs. We detected isolated cases of fish infection with diplostomiasis in roach from Lake Toxumac, where IR was $12.5 \%$. This is due to the presence of gulls and pond mollusks on this lake, which are the main links in the helminth's life cycle. We have also identified isolated cases of ligulosis in roach and crucian carp from the "DSU-58" dam, where, respectively, IR was 27 and $14.2 \%$. The presence of this disease is associated with the presence of fish-eating birds and crustaceans in this pond.
\end{abstract}

\begin{tabular}{l} 
Article Information \\
Received 09 December 2019 \\
Revised 14 May 2020 \\
Accepted 19 June 2020 \\
Available online 27 November 2020 \\
Authors' Contribution \\
\hline GA and ZA conceived and planned \\
the study. AI and AZ conducted lab \\
work and drafted the manuscript. \\
AA did statistical analysed the data. \\
GArevised the manuscript. \\
Key words \\
\hline Fish safety, Biological productivity, \\
Trophicity of the lakes, Hydrochemical \\
regime, Aeromonosis
\end{tabular}

Article Information Revised 14 May 2020 Accepted 19 June 2020 Available online 27 November 2020

' Contribution A and $Z A$ conceived and planned the study. AI and AZ conducted lab work and drafted the manuscript. AA did statistical analysed the data. Fish safety, Biological productivity, regime, Aeromonosis

\section{INTRODUCTION}

$\mathrm{K}$ azakhstan has a significant fund of small and medium-sized reservoirs with high profitability for the cultivation of marketable fish. However, the use of such reservoirs at present, most often, is irrational. In this regard, a comprehensive study of them is aimed primarily at the development of fisheries (Maikanov et al., 2014).

Inland fisheries, which can range from individual fishers to large commercial enterprises, are an important source of food raw materials, especially at the local level. There are 599 water bodies in the region, including 107 rivers, 83 lakes, 409 artificial reservoirs and dams with hydraulic structures. In the list of fishery reservoirs of the Karaganda region, of $11 / 29 / 2018$, there were 130

\footnotetext{
* Corresponding author: kadr_90.taz@mail.ru 0030-9923/2021/0001-0027 \$ 9.00/0

Copyright 2021 Zoological Society of Pakistan
}

reservoirs and 174 sections, of which 68 reservoirs and 96 sections were fixed. The total number of reserve reservoirs (sections) was 65 reservoirs and 78 sections.

The anthropogenic activity has great impact on the biocenosis of water bodies, which in turn affects the hydrochemical composition of water bodies, negatively affecting zooplankton and ichthyofauna. Anthropogenic impact factors include widespread use of various protective equipment in agriculture, insufficient wastewater treatment of industrial and municipal enterprises, removal of radioisotopes into the environment from uranium mining enterprises, which leads to increasing pollution of fishery ponds with compounds toxic to aquatic organisms (Brzoska and Moniuszko-Jakoniuk, 2011; Culotta and Gitlin, 1999). Meanwhile, it is known that fish in the early stages of development are most sensitive to toxic environmental factors, they are more susceptible to mass death from infections and infestations when exposed to pollutants (Makangali et al., 2019; Virbickas et al., 2000). 
Analyzing the environmental issue at the moment, the Karaganda region is one of the ecologically unfavorable territories. This is due to the large concentration of ferrous and non-ferrous metallurgy enterprises, energy complexes and other industrial facilities. Often, at these enterprises, process gases are released into the atmosphere without purification from sulfur dioxide and dust containing heavy metals - copper, lead, arsenic, etc. In this regard, the study of the fisheries potential of the middle water bodies of the Karaganda region, as well as the influence of technogenic factors on fish safety indicators, of course, is timely and relevant. The aim of the work is to determine the hydrochemical regime of water bodies and assess the safety of fish caught in water bodies of the Karaganda region. To achieve the goal, the following tasks were set: to study the organoleptic limiting indicators of water, oxidizability and oxygen regime of water bodies. When assessing the safety of fish, examine the infection of fish with helminthiases and bacterioses, determine the residual amounts of toxic elements and radionuclides.

\section{MATERIALS AND METHODS}

We undertook an expeditionary trip to the lakes of the Karaganda region, where water and fish samples were taken from various water bodies (Lake Balyktykol of the Karkaraly region, Lake Toksumak of the Osakarovsky district, Dam of branch No. 1 of the village of Pokornoye, Bukharzhyrau district, Dam DSU-58 of the Nurinsky district) for research.

Hydrochemical studies were carried out on the surface and bottom layers of water according to generally accepted methods, i.e., water was taken from depths of $30-40 \mathrm{~cm}$ into plastic containers with a volume of 1 liter. All dishes were pre-prepared according to the rules for preparing containers before sampling to prevent. The composition and properties of water were determined by two methods - titrometric and colorimetric according to existing methods. The $\mathrm{pH}$ of the water was measured with a testo $206 \mathrm{pH}$ meter (Testo AG Germany).

Water samples (120) were taken from three stations. Organoleptic limiting indicators of water (taste, smell, color, turbidity, transparency), oxidation and oxygen regime of water were studied.

Five species of fish were studied (crucian carp, tench, perch, roach, carp). A total of 176 fish specimens were studied. Sampling of fish was carried out directly from water bodies. In determining the safety of fish, we studied the infection of helminthiases, bacterioses, as well as the degree of contamination with its toxic elements and radionuclides. Helminth infections were studied in scales, gills, eyes, internal organs and muscles by visual and compressor methods. The goal was to identify the most common helminthiases- trienophorosis, ligulosis, diplostomatosis, postdiplostomatosis, phylometroidosis, larvae of tape and round helminths, and also to conduct studies on opisthorchiasis, metahonymosis and diphyllobothriasis. For detecting the presence of bacteriosis by clinical examination, skin and fins were carefully examined, attention was paid to the quantity and quality of mucus, discolouration, swelling, hemorrhage, ulcers, scars, cysts, scaling, etc., then gill covers were lifted and examined the gills. The registration of sick fish was carried out in absolute and percentage terms (incidence) (Antiepidemic measures: Official Documents Collection, 2006; Malovastyj, 2013).

The degree of contamination of fish with toxic elements and radionuclides was determined on the basis of the RSE for PHC "Republican Veterinary Laboratory" of the Committee for Veterinary Control and Supervision of the Ministry of Agriculture of the Republic of Kazakhstan in the accredited laboratory "Food Safety Analysis" (international standard ISO/ IEC17025). The study on the presence of toxic elements in fish (lead, mercury, cadmium and arsenic) was carried out on a TA-Lab voltammetric analyzer. Radioactive contamination was determined by the number of cesium-137 and strontium-90 radionuclides on the "Progress BG" beta-gamma spectrometric complex (Russian-made TOM-ANALIT). A total of 27 fish samples were examined.

Statistical analysis of the material was carried out using the Microsoft Excel application package. The mean value $(\bar{x})$, mean error $(\mathrm{S} \bar{x})$, standard deviation $(\sigma)$, coefficient of variation $(C v)$ were calculated. The difference between the average values was evaluated by Student's test and $\mathrm{p}$-value, which was recognized as statistically significant at $\mathrm{P} \geq 0.95$, according to A.N. Plokhinsky and other scientists (Plokhinskii, 1961; Lakin,1973; Vasilyeva, 2004).

\section{RESULTS AND DISCUSSION}

Table I shows the organoleptic indicators of water. We used the standards for determining the nature and intensity of taste and smell. As can be seen in the four reservoirs, the taste and smell was equal to 1 point, which indicates that the taste and smell were detected during testing in the laboratory. The color of water in four reservoirs was within normal limits. Transparency data also showed the normal limit. The turbidity was determined by the method No. 6.153 ("by font"). Formazin turbidity was normal and did not exceed $0.2 \mathrm{mg} / \mathrm{L}$. In general, according to organoleptic limiting indicators in four reservoirs, the hydrochemical regime of water in the spring was within the allowable concentration. 
The criterion for judging the intensity of biochemical oxygen consumption was the value of its oxidizability. The higher the oxidizability, the lower the water quality (Table II). The level of permanganate oxidizability in water bodies was as low as $3.28-3.33 \mathrm{mg} / \mathrm{l}$. Indicators of oxidizability in natural water sources vary, and depend on the biological productivity of the object. A high oxygen content was noted in Lake Balyktykol ( $8.9 \mathrm{mg} / \mathrm{l})$. The oxygen balance was at the level of $1.88-3.5 \mathrm{mg} / \mathrm{L}$. Thus, there was no oxygen deficiency in the studied water bodies, permaganate oxidizability was lower, which indicates that the water quality is in satisfactory condition.

Table III shows fish infection during fish studies for the presence of helminthiases-posthdiplostomosis (Posthodiplostomum cuticola), diplostomosis (Diplostomum spathaceum) and ligulosis (Ligula intestinalis). Thus, when examining fish from a reservoir, dam No. 1 of the Bukhar-Zhyrau distict, we found the larval stages of postdiplostomatosis (caused by the trematode Posthodiplostomum cuticola) in 2 out of 16 examined roach, while the infestation rate was $12.5 \%$ and the intensity was $2-3$ cysts, of 26 examined crucian carp, none were infected with helminthiases.

In Toksumak lake of Osakarovsky district, 3 fish specimens out of 16 studied roach specimens characteristic signs of posthodiplostomosis were found, the infestation rate was $18.7 \%$, and the infestation intensity varied from 2 to 7 cysts. When examining the lens of two fish specimens, metacercariae Diplostomum spathaceum were detected, with an infestation rate of $12.5 \%$ and an intensity of $1-2$.

Table I. Organoleptic limiting indicators of water bodies of water in the Karaganda region.

\begin{tabular}{llllll}
\hline Lakes & $\begin{array}{l}\text { Taste } \\
\text { (point) }\end{array}$ & $\begin{array}{l}\text { Smell } \\
\text { (point) }\end{array}$ & $\begin{array}{l}\text { Color } \\
\left({ }^{\circ} \mathbf{C}\right)\end{array}$ & $\begin{array}{l}\text { Transparenc } \\
(\mathbf{c m})\end{array}$ & \multicolumn{2}{c}{ Turbidity of water (mg/L) } & Kaolin \\
\hline Balyktykol & 1 & 1 & $50 \pm 0.02$ & 45 & $0.5 \pm 0.001$ \\
Toksumak & 1 & 1 & $53 \pm 0.03$ & 50 & $0.6 \pm 0.0012$ \\
Dam No. 1 & 1 & 1 & $50 \pm 0.02$ & 47 & $0.5 \pm 0.001$ \\
Dam DSU-58 & 1 & 1 & $50 \pm 0.02$ & 50 & $0.5 \pm 0.001$ \\
\hline
\end{tabular}

Table II. Oxidizability and oxygen regime of water (mg / L) (spring).

\begin{tabular}{lllll}
\hline Indicator & Lake Balyktykol & Lake Toksumak & Dam No. 1 & Dam DSU-58 \\
\hline Oxidizability (mg/ L) & $3.28 \pm 0.33$ & $3.4 \pm 0.36$ & $3.9 \pm 0.34$ & $3.7 \pm 0.34$ \\
$\mathrm{O}_{2}$ content in water (mg/ L): & & & & \\
$\quad$ - at the surface & $8.9 \pm 0.27$ & $7.4 \pm 0.21$ & $7.8 \pm 0.24$ & $7.8 \pm 0.24$ \\
$\quad$ - at the bottom & $5.61 \pm 0.15$ & $5.52 \pm 0.13$ & $4.3 \pm 0.11$ & $4.5 \pm 0.12$ \\
$\quad$ Balance & $3.29 \pm 0.11$ & $1.88 \pm 0.01$ & $3.5 \pm 0.10$ & $3.3 \pm 0.11$ \\
\hline
\end{tabular}

Table III. Infection with helminthiases of fish in water bodies of the Karaganda region.

\begin{tabular}{|c|c|c|c|c|c|}
\hline \multirow[t]{2}{*}{ Type of fish } & \multicolumn{2}{|c|}{ Quantity of fish } & \multirow[t]{2}{*}{ Type of parasite } & \multirow[t]{2}{*}{ IR, $\%$} & \multirow[t]{2}{*}{ II, specimens } \\
\hline & Examined & Infested & & & \\
\hline \multicolumn{6}{|c|}{ Dam No. 1 (Bukharzhyrau district) } \\
\hline Crucian carp & 32 & Not detected & - & - & - \\
\hline Roach & 16 & 2 & Posthodiplostomum cuticula & 12.5 & $2-3$ \\
\hline \multicolumn{6}{|c|}{ Lake Toksumak (Osakarovsky district) } \\
\hline Crucian carp & 26 & Not detected & - & - & - \\
\hline \multirow[t]{2}{*}{ Roach } & 16 & 3 & Posthodiplostomum cuticula & 18.7 & $2-7$ \\
\hline & & 2 & Diplostomum spathaceum & 12.5 & 2 \\
\hline Perch & 12 & Not detected & - & - & - \\
\hline Carp & 13 & Not detected & - & - & - \\
\hline \multicolumn{6}{|c|}{ Dam “DSU-58” (Nurinsky district) } \\
\hline Crucian carp & 27 & 4 & Ligula intestinalis & 27 & $3-5$ \\
\hline Tench & 10 & Not detected & - & - & - \\
\hline \multirow[t]{2}{*}{ Roach } & 14 & 6 & Posthodiplostomum cuticula & 42.8 & $3-5$ \\
\hline & & 2 & Ligula intestinalis & 14.2 & $2-3$ \\
\hline
\end{tabular}


Table IV. Contamination of fish with toxic elements selected from various water bodies of the Karaganda region and the markets of Nur-Sultan city ( $\mathrm{mg} / \mathrm{kg})$.

\begin{tabular}{lllll}
\hline Toxic elements & TLV & \multicolumn{3}{c}{ Water bodies (districts) } \\
\cline { 3 - 5 } & & $\begin{array}{l}\text { Dam No. 1 (Bukharzhyrau } \\
\text { district) } \mathbf{n}=\mathbf{6}\end{array}$ & $\begin{array}{l}\text { Lake Toksumak (Osakarovsky } \\
\text { district) } \mathbf{n}=\mathbf{6}\end{array}$ & $\begin{array}{l}\text { Dam DSU-58 (Nurinsky } \\
\text { district) } \mathbf{n}=\mathbf{6}\end{array}$ \\
\hline Cadmium & 0.2 & $0.0023 \pm 0.002$ & $0.0018 \pm 0.001$ & $0.0026 \pm 0.002$ \\
Lead & 1.0 & $0.0017 \pm 0.000$ & $0.0019 \pm 0.001$ & $0.0031 \pm 0.000$ \\
Mercury & 0.6 & $0.0003 \pm 0.001$ & $0.0005 \pm 0.000$ & $0.0005 \pm 0.001$ \\
Arsenic & 1.0 & vestige & $0.0022 \pm 0.002$ & $0.0022 \pm 0.000$ \\
\hline
\end{tabular}

No helminthiases were detected in samples of perch and carp. The fish studies of the dam "DSU-58" in Nurinsky district shows, that 4 out of 27 examined crucian carps were infected with ligulosis, the infestation rate was $14.8 \%$ and the intensity was 3-7 larvae. Posthodiplostomosis was observed in 6 roach specimens out of 14 examined, the infestation rate was $42.8 \%$ and the intensity was $3-5$ cysts. Ligulosis was detected in two fish specimens, with the infestation rate $14.2 \%$ and the intensity of 2-3 specimens. Helminthiases was not found in Tench specimens. Consequently, the most common fish disease in water bodies of the Karaganda region is postdiplostomatosis, which was diagnosed in fish in all water bodies of three regions. In rare cases, diplostomiasis was found in the roach (Lake Toksumak) and ligulosis in the roach and crucian carp (DSU-58). At the same time, the DSU-58 reservoir of the Nurinsky district is the most unfavorable for helminth infections, where the percentage of infection (the infestation rate) was the highest. When studying the infection of fish with bacterioses, in isolated cases, silver crucian carp was affected by aeromonosis (rubella carp) from the reservoir "DSU-58" of the Nurinsky district. Bacterioses were not found in fish from other water bodies.

Table IV shows the toxic elements in fish meat from water bodies located in different regions of the Karaganda region. As can be seen, the residual amounts of toxic elements were found in small quantities and no excess TLV was observed. Thus, in terms of cadmium and lead content, the greatest accumulation is observed in fish meat from the dam "DSU-58" (Nurinsky district), where its amount was 0.0026 and $0.0031 \mathrm{mg} / \mathrm{kg}$, respectively. In the Toksumak Lake (Osakarovsky District), 0.0018 and $0.0019 \mathrm{mg} / \mathrm{kg}$, respectively, and in fish from Dam No. 1 (Bukhar-Zhyrau District), 0.0023 and $0.0017 \mathrm{mg} / \mathrm{kg}$. The mercury content in fish from all those reservoirs did not differ much, arsenic was not found in fish from dam No. 1, and in fish from Lake Toksumak and dam "DSU 58", the same amounts were found $-0.0022 \mathrm{mg} / \mathrm{kg}$.

In determining radionuclides in fish meat, their residual amount was not detected, with the exception of a single case in fish from Dam No. 1 (Bukhar-Zhyrau region), where its amount is $8.4 \mathrm{~Bq} / \mathrm{kg}$, with the normal quantity of $100 \mathrm{~Bq} / \mathrm{kg}$.

\section{CONCLUSION}

Thus, the hydrochemical indicators of water in Lake Balyktykol, Dam No. 1 and Dam "DSU-58" were within the TLV, while in Lake Toksumak it exceeded 3 degrees in terms of color. Exceeding this indicator indicates moderate pollution of the reservoir. According to O.A. Alekin's classification Lake Toksumak belongs to the hydrocarbonate class, sodium group, the second type; Balyktykol lake belongs to the hydrocarbonate class, calcium group, the first type; Dam No. 1 - sulfate class, calcium group, the first type; DSU-58 dam - to chloride class, calcium group, first type. Contamination of toxic elements of fish in water bodies of the Karaganda region is insignificant; fish in the dam "DSU-58" are most contaminated with mercury and lead. No residual radionuclides were found in the fish. When using residual amounts of toxic elements and radionuclides in fish meat, exceeding the maximum permissible concentrations has not been established. The most contaminated with mercury and lead was fish from the dam "DSU-58" of the Nurinsky district. Perhaps this is due to the fact that this body of water is located near the Nura River, which is often polluted by industrial discharges by the metallurgical plants of the city of Temirtau; during a spring river flooding, water from it can enter the water body. In addition, this water body is drainless, which possibly also contributes to a greater accumulation of toxic elements. As a result, heavy metals may accumulate in the aquatic organism, leading to mortality or malfunctions; and passing along the trophic chains, including to humans, which can lead to various diseases.

\section{Statement of conflict of Interest}

The authors have declared no conflict of interest.

\section{REFERENCES}

Anti-epidemic measures: Official Documents 
Collection. 2006. MUK 3.2.988-00 Methods of sanitary-parasitological examination of fish, shellfish, crustaceans, amphibians, reptiles and their processed products. Moscow. V.1.

Brzoska, M.M. and Moniuszko-Jakoniuk, 2001. Interaction between cadmium and zinc in the organism. Fd. Chem. Toxicol., 39: 967-980. https:// doi.org/10.1016/S0278-6915(01)00048-5

Culotta, V.C. and Gitlin, J.D., 1999. Disorders of copper transport. The molecular and metabolic basis of inherited disease. McGraw-Hill, Wash. (D.C.), pp. 210-221.

Lakin, G.F., 1973. Biometrics, Moskow.

Maikanov, B.S., Pishenko, Y.V. and Aubakirova, G.A., 2014. Comprehensive study of the Ashykol and Kumkol Lakes of Akmola Oblast of the North
Kazakhstan. Mediterr. J. Soc. Sci., 5: 2607-2611.

Makangali, K., Konysbaeva, D., Zhakupova, G., Gorbulya, V. and Suyundikova, Zh., 2019. Study of sea buckthorn seed powder effect on the production of cooked-smoked meat products from camel meat and beef. Periodico Tche Quimica, 16: 130-139.

Malovastyj, K.S., 2013. Diagnosis of diseases and veterinary sanitary examination of fish.

Plokhinskii, A.N., 1961. Biometrics, Novosibirsk.

Vasilyeva, L.A., 2004. Statistical methods in biology. Tutorial to the lecture course "Biometrics".

Virbickas, Y.B., Vosyliene, M.Z. and Kazlauskiene, N.P., 2000. A comprehensive study of the effects of TM mixtures on fish. Conf. Ecol. Physiol. Fish Biochem. Tesas. Doc. Yaroslavl, pp. 48-50. 